\title{
Trocas intergeracionais e construção de fronteiras sociais na França
}

\author{
Monique de Saint-Martin, \\ Daniella de Castro Rocha e Mariana Heredia \\ Tradução de Ana Cristina Arantes Nasser
}

A sociedade francesa é, inegavelmente, como muitas sociedades contemporâneas, uma sociedade individualizante e individualizada, mas é também atravessada por divisões que definem as diversas categorias e as diferentes classes no seu interior. As antigas desigualdades socioeconômicas perduram em larga medida, e as novas desigualdades se manifestam, particularmente nos últimos anos, com a desestabilização crescente das posições sociais e profissionais. Se as inserçōes profissionais parecem, assim, tornar-se menos sólidas, as clivagens sociogeográficas revelam-se, em geral, mais acentuadas. Diante do declínio relativo das classes médias e da pauperização das classes populares, as fronteiras de vizinhança foram efetivamente endurecidas, cada grupo tendendo a fugir ou a evitar o grupo situado numa posição inferior à sua (Maurin, 2004).

Portanto, a noção de fronteira é essencial à compreensão dos grupos sociais ${ }^{1}$. De um lado, elas delimitam os contornos das categorias sociais - a participação desigual dos indivíduos na vida social - e, de outro lado, abrem espaços de troca e de encontro para que as classes se comuniquem entre si. Com efeito, como Fredrik Barth o havia ressaltado ([1969 $\left.]^{*} 1995\right)$, a fronteira separa e possibilita as trocas entre duas unidades que se reconhecem mutuamente como diferentes. Essa noção constitui uma ferramenta teórico-metodológica particularmente pertinente para refletir sobre as formas doravante múltiplas de manutenção e de recomposição da distância entre
1. A noção de "fronteira social" só foi conceituada recentemente nas ciências sociais. E os trabalhos empreendidos por diferentes autores, como Gérard Althabe, Pierre Bourdieu, Michèle Lamont, Charles Tilly ou Christian Topolov, entre outros, permitem lhe conferir uma certacentralidade na explicação das formas de inserção coletiva e na descrição das dinâmicas de diferenciação social. Se o projeto do qual provém esteartigoseinteressou por várias definiçōes da noção de "fronteira", a abordagem desenvolvida concentra-se na formulaçãodeCharles Tilly 
(2004 e 2005). Para este autor, as fronteiras "nos" separam "deles", e interrompem, circunscrevem ou "produzem segregação" em distribuiçõos de populações ou de atividades no interior das sociedades. As questōes da transformação são centrais nessa abordagem. Dois tipos de mecanismos - os que aceleram a transformação das fronteiras e os que constituem a transformação das fronteiras-intervêm no processo próprio à formação das fronteiras.

*A data entre colchetes refere-se à edição original da obra. Ela é indicada na primeira vez que a obra é citada. Nas demais, indica-se somente a edição utilizada pelo autor (N.E.).

2. Essa pesquisa foi realizada no Centro de Estudo dos Movimentos Sociais (Cems); o conjunto dos resultados do estudo compôs um relatório final (Saint Martin e Gheorghiu, 2007). As análises desenvolvidas, principalmente no capítulo IV, constituem o ponto de partida do presente artigo, que também se baseia em análises elaboradas pelos outros autores do relatório, em outros ca- os diferentes grupos sociais em sociedades marcadas por processos mais ou menos vigorosos de recomposição do social.

Buscando apreender os processos de construção, inculcação e fragilização de fronteiras sociais hierarquizadas, uma pesquisa coletiva foi realizada entre 2004 e 2007, junto aos diferentes grupos que constituem a sociedade francesa; ela se baseia principalmente em um conjunto de 63 entrevistas aprofundadas e, eventualmente, repetidas junto a 28 famílias (38 pais e 25 jovens de 12 a 21 anos), em Paris, no subúrbio parisiense - em Gennevilliers, Noisy le Grand, e Sarcelles -, e em duas cidades da província, Estrasburgo e Le Havre². Observando a produção, a reprodução, a intensificação e/ou o enfraquecimento das fronteiras pelos membros de cada um dos grupos, um dos objetivos dessa pesquisa era contribuir para um estudo comparativo das classes sociais em diversas sociedades contemporâneas (França, Romênia, Suécia, Brasil), atribuindo uma importância central à minúcia do cotidiano e à educação que se realiza fora do sistema escolar, particularmente no seio da família e das associações, sem, no entanto, ignorar a escola.

As fronteiras sociais desempenham, às vezes, o papel de uma "muralha" que protege de riscos, e, noutras vezes, representam um "fosso" a ser transposto em busca de escapatória. Cada fronteira atravessada marca as histórias familiais em um sentido positivo (de promoção) para uns e, negativo (de desclassificação) para outros. Assim, as fronteiras representam as linhas que os membros de cada família experimentaram, em conjunto ou individualmente, em sua travessia no espaço social. Nesse jogo de deslocamentos, desejados ou sofridos, que se intensificou nos últimos anos, estabelece-se um ponto de partida para rever a pertinência da noção de classe social.

Estamos interessadas, primeiramente, pela construção simbólica e a percepção de fronteiras mais ou menos estanques, que separam as classes e os grupos sociais e possibilitam as trocas entre eles, e também pela construção de fronteiras no interior dos diferentes grupos ou classes levantados na pesquisa, tentando apreender essas construçôes como processos, e não como já "dadas" por meio de uma espécie de inconsciente cultural. Essa abordagem "processual" permite observar as antigas desigualdades "em ação", e as novas desigualdades "em construção" ${ }^{3}$, bem como prestar uma atenção particular à dimensão instável e móvel dessas fronteiras sociais, assim como à instabilidade das posiçóes ocupadas por várias das famílias pesquisadas. "A instabilidade de posição" é pensada, aqui, numa perspectiva ampla, na medida em que pode adquirir significaçôes muito variadas nos diferentes grupos sociais. Ela é considerada como sendo determinada, em grande parte, por cer- 
to descompasso entre os recursos (parcos) detidos por um indivíduo (ou família) e a posição social que ele ocupa ou reivindica; a debilidade dos recursos podendo residir tanto na dimensão objetivamente precária da posição ocupada, como em seu caráter móvel, ou ainda em seu caráter recente, bem como o pequeno reconhecimento que isso implica.

\section{Um retorno às classes sociais?}

Objeto de debates intelectuais fecundos e polarizados que atravessaram o século XX, a noção de classe social foi freqüentemente revisada, complexificada, e, em geral, rechaçada. Após os estudos sobre a estratificação social que pressupunham, amiúde, uma intensa fluidez nas sociedades ocidentais - particularmente pela via da mobilidade intergeracional ascendente -, a noção de classe social conheceu uma renovação nos anos de 1960 e de 1970. Com efeito, as abordagens provenientes da tradição marxista e weberiana encontraram uma síntese na obra de Pierre Bourdieu, dos pesquisadores que trabalhavam com ele e nas análises dos historiadores ingleses. Geralmente circunscrita às posiçôes ocupadas no âmbito da produção econômica, a noção de classe social adquiriu, em Bourdieu, dimensões sociais e culturais não menos determinantes. Efetivamente, para o autor de La distinction (1979), a relação com a escola, os gostos alimentares ou musicais, ou a escolha da decoração para a moradia, para tomar apenas estes exemplos, estabeleciam diferenças substanciais entre os membros de classes sociais diferentes. Edward Thompson ([1963] 1988, p. 15) enfatizava, de sua parte, o fato de que uma classe social constituía uma "formação social e cultural" oriunda de um processo histórico. Era, assim, na oposiçãao a outros grupos e na construção de formas institucionais próprias, que os grupos sociais se reconheciam como fazendo parte de uma classe.

A rejeição à noção de classe social não adveio, nos anos de 1980 e de 1990, da atualização das teorias sobre a individualização positiva e a mobilidade social ascendente. Ao contrário, a emergência de uma "nova questão social" e a desestruturação regressiva do mercado de trabalho assinalavam a insuficiência das categorias profissionais que serviam, até então, para classificar os membros das sociedades capitalistas. Paralelamente, as formas de identificação e mobilização coletivas pareciam cada vez menos voltadas para a oposição entre capitalistas e trabalhadores: os agrupamentos étnicos, sexuais, ecológicos introduziam-se com força, marginalizando, por vezes, os protestos e as demandas dos sindicatos. Assim, para alguns autores (cf. pítulos. Queremos agradecer a membros da equipe do Cems: M. Dinu Gheorghiu, P. Gruson, D. Merklen, L. Labache, B. Bauchat e J. Vari, pela contribuição às análises aqui propostas.

3. Em realidade, as novas linhas de divisão não se deixam apreender facilmente, e as dimensóes espacial e escolar são muito importantes na nova estruturação das desigualdades (Lagrange, 2006). 
Pakulski, 1993), a categoria de classe tornava-se duplamente problemática. De um lado, ela não era mais adequada como "cartografia" da sociedade, já que a composição dos grupos sociais havia se tornado demasiado instável, complexa e opaca para se ajustar à noção de classe. De outro lado, não servia mais para explicar a mudança social, uma vez que os conflitos sociais e políticos não mais correspondiam aos antagonismos de classe.

Mais recentemente, todavia, pode-se constatar, após esse período de relativo "adormecimento" (associado à idéia bastante difundida do "declínio" das classes), certo retorno à problematização das classes sociais (cf. Bouffartigue, 2004). O discurso sociológico busca novamente apreender as realidades e desigualdades sociais atuais e, ao mesmo tempo, introduzir uma renovação em uma de suas categorias conceituais mais clássicas.

Enquanto diferentes autores insistem no caráter, hoje, "totalmente obsoleto" da categoria classe social (para um exemplo, ver Urry, 2005), parece necessário discutir a pertinência e a atualidade de uma leitura do mundo contemporâneo em termos de classes sociais. A reativação recente desta problemática não se dá, aliás, sem relação com as metamorfoses objetivas da questão social e do mundo econômico, que se impõem de formas e em escalas variáveis nos diferentes países, mas que constituem, sem dúvida, tendências bastante gerais e transfronteiriças. Atendo-se ao exemplo francês, é possível observar que as mutaçôes socioeconômicas recentes, que se traduziram por uma desaceleração do crescimento econômico, um recrudescimento das desigualdades na distribuição das rendas e nas condições de vida, uma precarização e uma flexibilização do emprego, contribuíram para reanimar

4. As questões suscitadas sobre esse tema são, primordialmente, polissêmicas, indo tanto no sentido da apologia, como no da recusa a um uso estanque desse aparato conceitual; ou ainda, da idéia de uma tendência à consolidação das classes, àquela de seu desaparecimento. os debates ${ }^{4}$ sobre as relações hierárquicas entre grupos sociais desiguais. Assim, a complexidade das recentes mudanças incita a observar as fronteiras, geralmente móveis, que separam as classes e organizam as "novas" posições dos indivíduos entre as classes sociais e no interior delas.

A noção de classe é utilizada aqui de modo flexível e operacional, a partir das hipóteses sociológicas surgidas na pesquisa, e tendo em conta a dimensão empírica complexa que ela adquire no contexto atual. Em outras palavras, as classes sociais não são consideradas conjuntos homogêneos baseados em posições econômicas estritas e em franca oposição, e tampouco como totalidades socioculturais sem fraturas e circunscritas às fronteiras nacionais. Efetivamente, as classes não são formadas em espaços fechados. Como salienta Anne-Catherine Wagner, se "as formas de identidade coletivas reconhecidas, a 'classe operária', os 'técnicos', os 'artesãos', resultam de longas e lentas elaborações, que se desenvolvem no seio do Estado-nação" (2007, pp. 
9 e 22), as hierarquias sociais se constroem, no entanto, cada vez mais em referência a espaços que ultrapassam o âmbito do Estado-nação, e a mundialização pode reativar as clivagens sociais.

Nessa ótica, a noção de classe não retém a atenção somente por permitir a descrição dos diferentes grupos que compõem as sociedades modernas. A particularidade dessa noção, muito marcada pela tradição crítica marxista, reside em evocar uma teoria da exploração e em estabelecer uma relação entre a riqueza dos ricos e a pobreza dos pobres, com os primeiros se apropriando de uma parte do trabalho dos segundos. Esta relação de dominação e de exploração inscrita na noção de classe é, aliás, geralmente diluída pelas descrições que utilizam as noções de exclusão ou de miséria social' ${ }^{5}$. A situação dos excluídos ou dos pobres requer, freqüentemente, uma tomada de consciência humanitária, assim como uma ajuda urgente, mas não se insere forçosamente na acusação dos grupos incluídos ou ricos, que não compartilham essas condiçōes degradadas de existência ${ }^{6}$.

A dimensão relacional é totalmente determinante para nossa abordagem, pois na experiência diferencial dos grupos que compõem a sociedade, é que são percebidos, com maior clareza, os componentes objetivos e subjetivos da noção de classe, bem como os mecanismos que permitem a reprodução das desigualdades sociais. Louis Chauvel propõe identificar grandes agrupamentos sociais perceptíveis de modo objetivo e subjetivo. Recorrendo provisoriamente à sua definição "intermediária" das classes, nós as consideraremos como grupos identificáveis:

[...] objetivamente pelo fato de que eles são hierarquizados, em situação conflitante na repartição dos recursos produtivos, principalmente do ponto de vista da detenção do poder e do capital que o acompanha; mas também subjetivamente identificados e observáveis por sua cultura, seus gostos, sua consciência de fazer parte de uma classe [...] (2006, p. 152) .

Essa definição permite pensar as relações entre as classes sociais e no interior delas em sua complexidade empírica. Possibilita também levar em conta, ao mesmo tempo, os efeitos das transformações econômicas (no sentido do crescimento), culturais (no sentido de uma "medianização") e educacionais (com a dita "democratização" escolar) ocorridas durante os "Trinta Gloriosos"* sobre as hierarquias sociais (sobretudo com a expansão das classes médias e a emergência de uma "nova classe média"), e as conseqüências de preferência fragmentares das transformaçōes recentes, dentre as quais
5. Ver, particularmente, a crítica proposta por Lojkine (2005) das análises em termos de excluídos e incluídos, que geralmente não levam em consideração a própria origem da exclusão social e de uma "ideologia individualista dominante", que tende a ignorar a questão do "interesse coletivo".

6. O que para Boltanski (1993) remete ao "tópico do sentimento", por oposição ao "tópico da acusação".

*Os "Trinta Gloriosos" se referem aos anos de forte crescimento econômico conhecido pela grande maioria dos países desenvolvidos, principalmente os paísesmembro da OCDE, entre 1945 (fim da Segunda Guerra Mundial) e 1973 (crise do petróleo). Cf. site http:/ /fr.wikipedia.org, acessado em 21/4/2008 (N.T.) 
7.A expressãoétomada de B. Bauchat (2006), que realizou uma pesquisa sobre a "burguesia de passagem", na província. a vulnerabilização, a desestabilização do mundo do trabalho e o crescimento de algumas diferenças sociais.

\section{As percepções das fronteiras sociais}

Buscando pensar as relações e as fronteiras entre classes e entre diferentes subgrupos, as variáveis levantadas no início desta investigação eram as mais indicativas do pertencimento dos indivíduos aos grupos sociais definidos previamente, a saber, as classes privilegiadas, médias e populares, e seus subgrupos "estáveis" e "instáveis" (ou "de passagem", no que concerne às classes privilegiadas). Para designar o pertencimento a uma classe determinada, e chegar a uma delimitação relativamente precisa das posições de classe, baseamo-nos na profissão dos indivíduos e também levamos em conta seu nível de instrução, seus locais de moradia (bairros) e seus modos de vida.

Esse pertencimento de classe e essa posição foram considerados como um dado inscrito na história dessas pessoas e dessas famílias. Observando a origem social (profissão dos pais, particularmente) dos adultos entrevistados, assim como a de seus cônjuges ou ex-cônjuges, foi possível traçar, mesmo que de maneira um pouco grosseira, as trajetórias de mobilidade (ascendente ou descendente) ou de estagnação social, identificando modelos familiais de ascensão social pela via escolar e outros por aliança matrimonial, além de também terem sido observados percursos menos ascendentes, e mesmo de desqualificação, geralmente ligados à migração.

A mobilidade geográfica e profissional foi igualmente levada em conta. Ela não implica necessariamente uma forma de "desestabilização social", e o processo ampliado de desestabilização social é vivido muito diferentemente nos diversos meios sociais. Assim, as famílias das classes privilegiadas com intensa mobilidade geográfica, denominadas “de passagem”, são às vezes estabilizadas por suas tradições e suas estratégias educacionais, enquanto uma grande mobilidade geográfica pode acarretar uma perda de referências e uma forma de instabilidade, por exemplo, para as classes populares imigrantes. Diante das experiências variáveis de instabilidade, um certo desejo de enraizamento parece contrariamente se desenvolver em algumas famílias, sobretudo nas classes populares e médias. A consolidação das redes de solidariedade constituídas territorialmente torna-se, assim, uma questão importante, permitindo "dispor de reservas de tipo relacional, cultural, econômico etc., que são as bases sobre as quais pode se apoiar a possibilidade de 
desenvolver estratégias individuais" (Castel e Haroche, 2001, p. 30), e, dessa forma, encontrar suportes passíveis de conferir uma proteção.

\section{As situações limítrofes}

Analisando os processos de construção das fronteiras sociais entre classes sociais e no interior delas, à luz das experiências educacionais familiais, uma primeira constatação logo se impôs: vários casos não podiam ser facilmente classificados nas três classes estabelecidas previamente (privilegiadas, médias e populares). Inúmeras famílias, por sua instabilidade ou sua mobilidade, situavam-se em posições limítrofes, o que confirmou, aliás, a pertinência de um procedimento analítico situado na confluência das abordagens dedutiva e indutiva.

Assim, foram agrupadas em uma classe "intermediária, média-popular", diferentes famílias que, por suas situaçōes limítrofes, não podiam ser classificadas em um contexto "típico" das classes médias ou das classes populares. As famílias representadas neste grupo intermediário têm em comum um percurso de mobilidade social mais ou menos ascendente conforme os casos, e descendente, em outros.

Foi, por vezes, difícil distinguir entre os estáveis e os instáveis no interior das diferentes classes levantadas, pois vários dos entrevistados haviam realizado percursos alternando estabilidade e instabilidade, ou, às vezes, se encontravam, no momento da pesquisa, entre a estabilidade e a instabilidade $^{8}$. Também foi introduzida uma categoria analítica intermediária, os "estáveis-instáveis", para designar essas pessoas que podiam, eventualmente, estar em via de "estabilização", ou que podiam viver numa estabilidade muito relativa.

Essas diferentes situações limítrofes, tratando-se das categorias intermediárias ou dos estáveis-instáveis, levaram à realização de um estudo das posiçôes sociais dos indivíduos sem limitá-las a categorias demasiado cristalizadas. Uma vez revelada a complexidade dessa primeira etapa de caracterização "objetiva" dos grupos, era preciso indagar sobre as dimensões "subjetivas", particularmente sobre as percepçōes das fronteiras sociais e seu caráter mais ou menos transponível.

Consideradas representaçóes assimétricas construídas de maneira relacional, as "percepçôes de classe" constituem um componente essencial e mesmo estruturante da manutenção e da transformação das hierarquias sociais, na medida em que elas participam da organização e da "identifi-
8. Os indicadores de estabilidade ou de instabilidade tiveram, por vezes, de ser diferenciados segundo os grupos sociais. Salvo para as pesquisas sobre as classes privilegiadas, o estatuto do emprego constituiu um indicador privilegiado. 
cação" de grupos e classes. Sem pretender identificar esquemas de percepção "próprios" a cada classe, trata-se de explicitar alguns elementos distintivos nas maneiras como as famílias das diferentes classes sociais percebem as fronteiras que as separam e/ou as aproximam das outras classes, bem como analisar até que ponto elas tendem a se definir por seu grupo de pertencimento, assim como pelas relações estabelecidas com os outros grupos sociais identificados. Essas identificaçôes e oposições contribuem para dar sentido à vida de cada pessoa: de um lado, elas servem para interpretar a vida de cada um - tornando-a compreensível - e, de outro, participam da mobilização de recursos pessoais e familiais, em vista de uma reprodução ou transformação da situação vivida. Essa mobilização é particularmente evidente entre as geraçôes, e constitui um elemento decisivo da experiência social e educacional que os pais buscam dominar e a partir da qual eles orientam a vida de seus filhos.

\section{A percepção do alto pelas classes populares: \\ "pobres" e "ricos", "imigrantes" e "puros sangue"}

Se os membros das classes populares entrevistados, principalmente aqueles oriundos da imigração, não mencionam nas entrevistas, a não ser muito raramente, as fronteiras entre classes, isso se deve pelo menos a dois motivos: um relativo ao desenvolvimento das entrevistas, quando nem sempre foi possível obter respostas precisas sobre o grupo do qual eles se sentiam próximos ou, ao contrário, distantes; o outro, referente à imposição do que se pode chamar provisoriamente de fronteiras étnicas, sobretudo para os que habitam Pavé Neuf, em Noisy le Grand, ou Luth, ou ainda Grésillons, em Gennevilliers - três bairros do subúrbio parisiense onde foi realizada a pesquisa, que apresentam uma taxa relativamente elevada de imigrantes - e que

9. As percepções das fronteiras étnicas podem por vezes se sobrepor a uma determinada percepção das fronteiras de classe ou das diferenças entre as populações instáveis e as populações estabelecidas. comentam, às vezes longamente, sobre a presença de diferentes grupos de origens nacionais distintas em seu meio próximo?

Quando inserida diretamente nas entrevistas, a questão da distância que separa esses membros das classes populares e das classes privilegiadas é apresentada como uma fronteira econômica; os outros, "eles", são os "ricos", os que têm muitos meios, principalmente financeiros, os que estão confortáveis, para quem a vida é mais fácil, diferentemente do "nós", que somos "pobres". A fronteira é também percebida como sendo de ordem social e relacionada com empregos e postos ocupados. Aqueles que conheceram uma mobilidade geográfica ou profissional e, conseqüente- 
mente, tiveram ocasião de se confrontar com outros grupos desenvolvem mais intensamente a consciência dessa distância e a exprimem de modo mais freqüente do que os membros das classes populares estabelecidos de longa data em seu bairro ou em seu emprego.

Originária do subúrbio e residente em Paris, onde foi inicialmente faxineira e depois agente técnica em um colégio, Joëlle, mãe de três filhos e divorciada, cuja posição é limítrofe entre estáveis e instáveis, percebe nitidamente as fronteiras sociais que separam seu grupo dos outros. Ela se sente próxima dos moradores de seu bairro, no 11을 distrito: "habitamos os mesmos imóveis $\mathrm{HLM}^{10}$, e são os pobres que moram aqui”. Dentre as pessoas com quem ela tem oportunidade de se relacionar, algumas são qualificadas como pertencentes à "alta" (sociedade) e identificadas por um determinado número de características, por exemplo, serem proprietárias de um apartamento amplo e luxuoso, terem uma "boa profissão", geralmente, postos de executivos, ou não terem necessidades financeiras. Joëlle constrói, às vezes, uma imagem idílica dessas famílias privilegiadas: "eles não são como eu, sempre contando os centavos. Eles estão numa situação confortável, eles não têm problemas. Eu digo sempre aos meus filhos, para que eles não conheçam a vida que eu...”

A "consciência" das barreiras que separam Joëlle das famílias privilegiadas não a impede, contudo, de tentar se aproximar deles em seu cotidiano. Inseridos na rede de relaçóes paroquial, Joëlle e seus filhos ali se encontram geralmente em interação com famílias provenientes de outros meios e, particularmente, das classes privilegiadas. Se a paróquia, como espaço de intersecção das fronteiras sociais e de relações, favorece o contato entre Joëlle e membros das classes privilegiadas, ela não deixa de atualizar as posiçóes hierarquizadas ocupadas no mundo social. Joëlle ocupa ali um lugar "dominado" e, ao se beneficiar do importante suporte psicológico, material e cultural das trocas sociais na paróquia, ela se encontra inserida em uma situação de distância social em relação àqueles que lhe prestam ajuda.

O topo da hierarquia social é, ao mesmo tempo, distante e próximo, e não é totalmente inacessível. Por um desejo de mudança em relação à sua situação atual, Joëlle cultiva grandes ambições para seus três filhos. Para ela, o sucesso profissional pressupõe trabalhar em um escritório. Ela não pára de citar para seus filhos a expressão "estou indo, vou ao escritório", que ela ouviu ser repetida por certos membros das famílias "burguesas". Da mesma forma, ela thes propõe modelos de identificação profissional externos ao seu meio, por exemplo, o médico ou o professor com quem se relaciona na
10. Os HLM são Habitações de Aluguel Moderado e designam moradias públicas ou subvencionadas pelo Estado, destinadas às pessoas e às famílias de recursos modestos. 
11. Ao contrário de sua mãe, que tem uma atitude resignada em relação à sua posição social, Malli, que é "rotulada" na escola como uma aluna particularmente "turbulenta", parece assumir uma postura que é mais de afrontamento ante os outros e as hierarquias. paróquia, dizendo a eles: "olhem, o senhor A ou a senhora B, eles têm boas profissões, eles não têm problemas de dinheiro, eles vivem em belos apartamentos... eu gostaria que vocês fossem como eles".

Diferentemente de Joëlle, cuja percepção "do alto" repousa nas experiências de vida concretas, em que ela esteve em contato com membros das classes privilegiadas, Fatou apresenta uma forma mais nuançada de percepção do alto. Para esta mãe de família proveniente do Mali e instalada em Sarcelles, os "outros", ao menos aqueles aos quais ela se refere, não são os "ricos". Os círculos de sociabilidade freqüentados por Fatou limitam-se essencialmente aos vizinhos (sobretudo os de origem africana), em seu imóvel HLM. A alteridade a que ela se reporta em seu discurso concerne menos às classes privilegiadas, as quais Fatou não parece representar de forma muito clara, do que aos outros habitantes de Sarcelles, particularmente os franceses em situação de aparente estabilidade, e que ela qualifica sempre como pessoas "gentis". Pouco eloqüente em torno dessas questôes, Fatou exprime, entretanto (sobretudo por sua atitude reservada e retraída), uma "consciência" de sua posição "subalterna" na sociedade francesa.

Essa percepção bastante vaga é identificada na filha adolescente de Fatou, Malli (14 anos). Sua visão do mundo social é fortemente condicionada, assim como a de sua mãe, pelo universo materializado em suas esferas de sociabilidade concretas, mais precisamente a escola e a vizinhança. $\mathrm{O}$ alto representa uma realidade desconhecida e está ausente de seu discurso, o que também se pôde observar em uma de suas colegas entrevistada juntamente com ela. Para Malli, os “outros” são aqueles aos quais ela se opõe ou se confronta ${ }^{11}$, em suas interaçôes cotidianas (na escola, ou, então, na cidade): principalmente, ao que parece, "os profs.", os alunos "cdfs", ou, ainda, os "clãs" de jovens de outros bairros. A distância social e/ou hierárquica em relação a esses "outros" parece se traduzir, às vezes, sob a forma de diferenças étnico-raciais. Os "nós" (segundo Malli, seus amigos e amigas são sempre negros ou árabes) opõem-se aos professores franceses "puro sangue", ou, ainda, aos "cdfs" brancos e, eventualmente, árabes. Sempre negando a existência do racismo na escola, as descrições que Malli faz de suas experiências escolares atestam que as fronteiras étnicas são constantemente reafirmadas, sendo o critério étnico um princípio de classificação inevitável. 


\section{A distância das classes médias e intermediárias para com as classes populares e os operários}

Os membros das famílias que ocupam posições médias ou intermediárias entre classes populares e classes médias podem encontrar dificuldades para se classificar, mas se identificam, geralmente, como pertencentes às classes médias. Em sua maioria, eles experimentaram, mais freqüentemente devido à escola e aos estudos, uma mobilidade social ascendente que se impóe como uma lógica de diferenciação em relação ao seu meio de origem. Eles falam muito pouco sobre as fronteiras em direção ao alto, que são, de certa forma, rechaçadas e evitadas, e insistem, primordialmente, sobre o que deve ser valorizado, sobre a mudança importante e mesmo sobre o salto realizado em relação à geração dos pais, graças a seus esforços. Entre aqueles que classificamos como intermediários, a preocupação em demarcar as fronteiras com a origem popular é particularmente reafirmada.

Este é o caso do casal Eliane - agente EDF (Eletricidade da França), proveniente de uma família de comerciantes - e Jean - cozinheiro que se tornou motorista de ônibus, o único da família que obteve um diploma, o CAP (Certificado de Aptidão Profissional), e oriundo de uma família popular enfrentando dificuldades econômicas no final de cada mês -, que foi classificado no grupo intermediário. Seus amigos, com quem se sentem em segurança, pertencem às classes médias em sentido amplo:

ELIANE: É sempre a mesma classe social. Eu me sentiria mal em um meio muito mais abastado, demasiado abastado.

JEAN: Sim, demasiado abastado; e a gente se sentiria mal também em um meio, por exemplo, de onde eu venho, um meio mais modesto, no qual eu morava em HLM e tudo, e é verdade que saí disso, e não sei como dizer, a gente não tem pontos comuns, não tem muita coisa a se dizer, não tem as mesmas atividades.

É principalmente pela distância tomada em relação à mãe de Jean e ao seu segundo marido, e pela evocação da fronteira transposta, que os separa do modesto meio de origem, que eles podem afirmar seu pertencimento à classe média:

ELIANE: É verdade que em sua família eles não tinham absolutamente centros de interesse.

JEAN: Ou seja, o problema é que viviam em HLM, e ficavam na sua HLM e, em 
seguida, era o trabalho, e após o trabalho, para meu pai, ele voltava para sua HLM e não se mexia, e retornava na segunda-feira ao trabalho, para mim, sem nenhum interesse.

ELIANE: Nós não temos nada em comum, sua mãe era muito das novelas na tv...

A distância admitida pelos pais em relação aos meios mais modestos é, em parte, observada nos discursos e nas experiências descritas por suas três filhas (de 20, 18 e 15 anos). Se, de maneira geral, elas não expressam claramente interesse pelo reforço das fronteiras sociais que as envolvem, não evocam menos as fronteiras que as separam dos grupos populares, e que são interiorizadas. Tendo conhecido uma educação familiar bastante "livre", e relativamente aberta, segundo seus próprios termos, nenhuma de suas filhas, em suas experiências cotidianas, parece buscar transgredir de maneira significativa as regras (vistas como primordialmente flexíveis) impostas pelos pais, ou então romper com o estilo de vida familiar. Ao contrário, por meio de seus relatos, observa-se mais uma tendência a preservar um certo "entre si", permanecendo "rodeadas de pessoas praticamente de nossa categoria social". Por outro lado, elas também se dizem distantes dos avós paternos e não buscam quase se aproximar deles. No que diz respeito aos seus círculos de sociabilidades, Magali, a mais velha e que, sem dúvida, interiorizou mais intensamente que suas irmãs o modelo familiar, relata: "eu me vejo menos com um operário, um pedreiro, ou algo semelhante... mas, bom, depois não digo que isso não possa acontecer...”. E acrescenta: “é normal se relacionar com as pessoas que são quase como nós". Longe de ser apresentada como uma recusa assumida do "outro", ou uma forma qualquer de discriminação, esse "entre si" aparece mais como uma forma de "desinteresse" - por vezes traduzido (quando isso concerne às suas preferências amorosas) em uma simples questão estética (ausência de atração física, quando se trata, por exemplo, de rapazes não-europeus).

A fronteira com o mundo popular e operário é também, freqüentemente, lembrada por aqueles que classificamos como membros das classes médias. É o caso de Claudette, educadora especializada, após ter sido professora durante vinte e cinco anos, e que atualmente ocupa uma posição social e profissional relativamente estável, graças aos seus estudos. Ela é oriunda de uma família popular; seu pai, de origem italiana, não estudou e era operário; sua mãe cuidava de crianças em casa, e mais tarde quando Claudette cresceu, passou a trabalhar "nos escritórios", como agente de controle. Em sua entrevista, Claudette faz menção à fronteira que a separa, e também sua 
família atual, do mundo popular e operário; seu segundo marido é técnico de enfermagem numa escola de formação de enfermeiros. No entanto, essa fronteira não é radical e alguns valores comuns são compartilhados - como indica certa moral da partilha entre os fracos, que lhe foi transmitida por seu pai e que ela reivindica como um valor a cultivar. No plano dos estudos, o bacharelado é considerado o diploma que delimita a fronteira entre as duas categorias, populares e médias. Em contrapartida, a "fronteira superior" não é praticamente lembrada na entrevista. A família parece estar mais mobilizada pela consolidação de uma posição adquirida, do que por investimentos em projetos de ascensão social para os filhos; todavia, certa esperança parece investida na superação do nível cultural e dessa condição, pelo filho mais novo.

\section{As classes privilegiadas: "conviver com classes sociais um pouco diferentes" e se aproximar dos que são próximos}

As famílias privilegiadas fazem grandes esforços para se proteger da vizinhança das classes médias e modestas; elas se reúnem e se agregam, e chegam a viver numa espécie de indiferença e de ignorância em relação aos outros grupos.

Tratando-se dos pais ou de seus filhos, os membros das classes privilegiadas, entrevistados em Estrasburgo, são, aliás, muito mais prolixos para falar de seu grupo, de seu "meio", do "nós", do que para falar dos "outros", muito pouco mencionados nas entrevistas e, principalmente, sem muitos comentários, referindo-se mais freqüentemente a "outros", sem maiores especificações.

Assim, os pais podem desejar que seus filhos sejam abertos para o mundo, viajem, tenham amigos em outros meios e "convivam com classes sociais um pouco diferentes" - para retomar a expressão de um dos pais de família entrevistados em Estrasburgo. Contudo, sua consciência do "nós", de fazer parte da burguesia, da necessidade de viver entre si, de controlar os relacionamentos dos filhos e de só aceitar como próximos e amigos pessoas muito pouco diferentes deles, não é menos forte se não mais forte quando um conjunto de práticas contribui para desenvolvê-la ${ }^{12}$. A escolha das escolas é significativa ${ }^{13}$, assim como o forte incentivo para que os filhos façam parte de associações, turmas de escoteiros, corais, ralis etc. As famílias mais "móveis" geograficamente mostram-se muito preocupadas, quando da chegada a uma nova cidade, em escolher para seus filhos se não os
12. A maneira de se vestir é tanto na geração dos pais como na dos filhos um elemento importante de distinção, uma característica que lhes permite menos o fato de serem reconhecidos pelos outros como burgueses, do que de se identificarem e se reconhecerem entre si (Le Wita e Sjögren, 1987). As maneiras de falar, de se dirigir aos outros, o vocabulário, constituem algumas das demais características.

13. Na pesquisa realizada em Estrasburgo, trata-se geralmente de escolas privadas e católicas. Contudo, de modo geral, são muitas as famílias das classes privilegiadas que procuram para seus filhos os estabelecimentos públicos de mais alta qualidade. 
locais mais seguros, ao menos aqueles em que eles não ficarão muito desorientados, e também em lhes possibilitar estudar os idiomas estrangeiros mais valorizados. Elas evitam correr riscos, temem grandes rupturas com o meio e se preocupam em lhes permitir uma rápida adaptação ao novo local de residência.

Para os jovens entrevistados nessas famílias, esse "nós" não é, certamente, o da "burguesia", mas é, em todo caso, aquele de um meio privilegiado - o de um grupo de amigos que se conhecem e se encontram amiúde, freqüentam as mesmas escolas, têm a mesma educação, as mesmas atividades e cujos pais geralmente se conhecem ou ao menos se cruzam, identificam-se e se reconhecem. Se é clara a consciência de fazer parte de um meio privilegiado, ela é, contudo, mais frágil, do que na geração de seus pais.

No entanto, nessas famílias, a fronteira com as outras classes pode, às vezes, ser explícita. Este é o caso da família de Sonia - cujo pai era suboficial, e a mãe, galerista -, em que a fronteira que separa grupos sociais situados mais abaixo na hierarquia social era lembrada aos filhos, enquanto Sonia, por sua vez, estimula seus próprios filhos a não transpô-la.

No que diz respeito aos militares... ao que me lembro, eu não tinha amigas filhas de oficiais, por exemplo. Em contrapartida, no que diz respeito aos civis, honestamente, eu tinha amigos um pouco em cada meio: amigas cujo pai era presidente de empresa, e amigas cujo pai era operário, eis aí. Minha mãe não queria muito que eu freqüentasse as amigas cujo pai era operário, ou algo semelhante, porque considerava que isso aproximava com o debaixo, mas, bem... isso não era grave.

Sonia tinha, efetivamente, explicitado estratégias que lhe permitiam evitar ou contornar o controle maternal. E declarando sua preocupação em não intervir demais nos relacionamentos de seus filhos, ela tenta fazer com que sua filha se conscientize de que é melhor não ter amigas que estariam abaixo na hierarquia social.

Apesar de pertinente, a delimitação previamente estabelecida entre as classes sociais demandou remanejamentos. Não somente as condições de vida continuam sendo diferentes nos diversos grupos, como também os membros de cada grupo se reconhecem como tendo atributos diferentes em relação aos outros. Em muitos casos, a percepção de si e dos outros insere-se nos contextos identificados por Bourdieu (1979). Nos meios populares, a oposição entre os pobres e os ricos permanece marcante, tanto quanto a vontade dos pais em ver seus filhos progredirem socialmente, 
apoiando-se sobretudo na escola. Às clivagens e às oposições socioeconômicas clássicas sobrepõem-se afinidades e desconfianças de origem étnica. Nas classes intermediárias e médias, a percepção de pertencer a uma categoria tão distinta das camadas inferiores quanto das elites continua a alimentar a aspiração a uma consolidação, e mesmo a um avanço na posição adquirida, graças, principalmente, à escola. Enfim, a forte identidade coletiva das famílias privilegiadas e suas relações controladas com os outros membros da sociedade reproduzem os princípios de troca, mas, sobretudo, de distinção social, estabelecendo o fechamento desses grupos a qualquer ingerência disruptiva do exterior.

\section{A construção das fronteiras interclasses: estáveis/instáveis ou precários}

As fronteiras não separam somente as classes, mas podem dividir também as próprias classes, a partir de diferenças de origem, de pertencimento a comunidades nacionais, políticas ou religiosas, ou ainda entre grupos "estabelecidos" ou "instalados" e grupos outsiders ou "instáveis". Se essa oposição entre estabelecidos e outsiders (Elias e Scotson, [1965] 1997), ou entre estáveis e instáveis, percorre toda a estrutura social, ela não recobre aí menos modalidades diferentes conforme os grupos.

Nas últimas décadas, o processo de precarização levou a certa "desestabilização" dos estáveis, inclusive nas zonas outrora estabilizadas do emprego. Em um plano mais geral, trata-se do enfraquecimento das proteções fornecidas pelo emprego e do questionamento da capacidade de trabalho em garantir a integração social (cf. Castel, 1995). No plano mais específico da organização interna do trabalho, trata-se da difusão do princípio da flexibilidade: pede-se aos trabalhadores que demonstrem flexibilidade, que estejam prontos a mudar de emprego rapidamente e que assumam constantemente riscos (Sennett, 2000). A idéia de uma carreira se construindo paulatinamente, bem como do desenvolvimento ao longo da vida de um só e único conjunto de competências, não tem mais quase fundamento. Do mesmo modo, a idéia de um emprego constituído como suporte dessa carreira e assegurando status e proteções à vida não é mais válida - ou, pelo menos, não o é para todos. As conseqüências desse processo não são uniformes e, sobretudo, não são sofridas da mesma maneira por todos os atores; assalariados do setor privado são, por definição, os mais expostos às transformaçôes do capitalismo contemporâneo (cf. Maurin, 2004, p. 23). Se alguns dispõem dos recursos necessários para "jogar 
* Encarregada do acolhimento de crianças em seu próprio domicílio ou em creches públicas ou privadas (N.R.). com" a instabilidade e fazer dela um trunfo, para outros ela não constitui senão uma coerção.

Aliás, talvez exista menos oposição entre indivíduos estáveis e indivíduos instáveis, do que entre diferentes graus e diferentes tipos de instabilidade. Os estabelecidos são, certamente, cada vez mais raros, no entanto eles constituem um ponto de referência importante na sociedade francesa.

\section{A consciência do "nós" nas classes populares "estáveis"}

Em face do desemprego, da precarização e da emergência da categoria dos "excluídos", a questão do sentimento de pertencimento a uma classe não perdeu toda a sua atualidade no seio dos meios populares. Assim, na família de Pascale e André e de suas três filhas, tal sentimento pode ser expresso nos discursos e nas atitudes em relação aos outros.

Tanto Pascale como sua filha mais velha, Jennifer, parecem ter uma consciência bastante acentuada de sua condição operária. Para a mãe, que foi faxineira e depois assistante maternelle ${ }^{*}$ e que hoje educa suas filhas, trata-se antes de uma visão "resignada" relativa a esse "lugar na sociedade" e aos limites que dele se deduzem. Ela e seu marido, que é reparador naval em Havre, adotaram um estilo de vida que consideram, com certo orgulho, compatível com seus meios e adequado à sua posição social (nada de férias nem viagens, e sociabilidade muito limitada). A aspiração à mobilidade social, sob quaisquer formas, está ausente do discurso de Pascale; as experiências educacionais que ela descreve quase não indicam estratégias escolares de ascensão social.

A consciência do "nós" exprime-se por um esforço de distinção e de resistência. Se, de um lado, essa família suporta - aceitando-as sem resistências - as fronteiras impostas "de cima para baixo", de outro, ela procura constantemente reafirmar suas diferenças com a população do bairro, composta em grande parte por famílias imigrantes que, apesar de um status econômico similar, parecem-lhe menos legítimas socialmente. A "legitimidade", ou, melhor, "autenticidade", é reivindicada por Pascale, invocando a antiguidade da família no bairro, sua condição de família francesa e os valores que ela transmite aos seus filhos. A polidez, a discrição, a recusa de qualquer extravagância na atitude e no comportamento dos filhos aparecem como princípios matriciais e distintivos das exigências morais cultivadas nessa família, sendo por isso que ela procura se diferenciar - principalmente das famílias imigrantes recém-chegadas ao bairro. A desconfiança 
em relação à vizinhança e a um mundo exterior bastante desconhecido é observável no controle (no sentido de certo fechamento) exercido sobre os filhos; eles não têm o direito de "ficar na rua", não freqüentam os centros de lazer e de férias, e não comem na cantina da escola.

A preocupação de distinção está longe, portanto, de ser o apanágio das classes superiores, e diferentes formas de "distinção" são empregadas, segundo modalidades e em proporçôes variáveis, nos diversos grupos sociais. A fronteira entre os estabelecidos e os outsiders, ou entre os antigos e os novos, é fortemente integrada nessa família, que a atualiza na educação (e nos valores) transmitida aos filhos.

O exemplo dessa família é ainda mais interessante pelo fato de que o "percurso familiar" conheceu, durante os três anos da pesquisa, mudanças que remetem, essencialmente, à história de Jennifer, e que pareceram, pelo menos de início, pôr à prova a identidade social (re)produzida e reafirmada com orgulho por seus membros. Jennifer, com 18 anos, e cursando uma escola profissionalizante, em 2005, expressava, então (tanto por seu discurso, como por seus projetos escolares e profissionais), uma continuidade identitária em relação a seus pais e incorporava fortemente o papel de filha tal qual lhe era imposto por eles. Ela não parecia querer transpor esses limites e deveria procurar um emprego de secretária, depois de se graduar. No entanto, um ano mais tarde, ela desenvolveu projetos pessoais e escolares bastante distantes de seu universo familiar e matriculou-se em Direito, na universidade. Seu encontro com Hakim, um jovem com quem logo depois ela se casou, e que por sua origem cabila (argelina) parecia "ameaçar" o "entre si" cultivado pela família, introduziu um elemento de descontinuidade. $\mathrm{O}$ esforço doravante expresso pelos pais no sentido da reafirmação e da recomposição de sua "consciência do nós" chama atenção para a dimensão móvel das fronteiras simbólicas e dos princípios de classificação que elas implicam em uma sociedade cada vez mais marcada pela multiplicidade étnica. Enquanto o estatuto de imigrante de Hakim recolocava em questão uma consciência do "nós" construída em grande medida por oposição às famílias de imigrantes já inseridas no bairro, os futuros sogros de Hakim apresentavam-no como um imigrante "diferente dos outros". A aceitação desse "recém-chegado" - estudante de informática - na família é legitimada no discurso de seus membros menos por uma valorização da alteridade que ele representa, do que pelas qualidades que ele evoca (sua polidez, inteligência, seu investimento no trabalho e sua capacidade de integração), e que segundo eles o distinguiriam dos imigrantes do bairro. 
A situação vivida por essa família revela, ao mesmo tempo, a desconfiança, geralmente latente, entre populaçōes locais e estrangeiras, e as possibilidades de superá-la. É efetivamente a mistura dos bairros populares que permitiu a Jennifer encontrar Hakim, e é certamente sua vontade de progredir que a encorajou a empreender uma formação universitária. Para a família, ainda que a diversidade cultural continue sendo uma fonte de inquietude, a ética do trabalho legitima a união com Hakim.

\section{Entre a proteção e o desejo de ascensão, ou como reconstruir uma posição "perdida"}

A família de Rajini e de Rajendra oferece um exemplo de posição social instável. Esta família, que se encontra hoje em um estrato mais elevado das classes médias, tornou-se, há uma dezena de anos, proprietária de sua moradia situada em um bairro popular, Pavé Neuf, da cidade de Noisy le Grand. O pai, Rajendra, é co-gerente de um pequeno restaurante do bairro indiano em Paris; a mãe, Rajini, é dona-de-casa e dedica-se à educação de seus três filhos, às atividades associativas, bem como, ocasionalmente, a trabalhos de tradução do inglês. As formas de instabilidade vividas por essa família se devem menos a seus recursos materiais atuais, do que a um percurso familiar de mobilidade social negativa e aos descompassos, vividos com mal-estar, entre seus recursos socioculturais e a posição ocupada na sociedade francesa.

Para apreender a instabilidade com a qual essa família é confrontada, é necessário retornar aos elementos de descontinuidade que marcaram as trajetórias sociais dos pais. Originários do Sri-Lanka, Rajini e seu marido Rajendra conheceram na Europa a experiência da desclassificação social. Tendo obtido na França o estatuto de refugiado político, sua "integração" no país pôde ser feita em parte graças ao apoio de associaçóes, em parte por sua inserção numa rede de solidariedade sri-lankesa, em cujo contexto esse casal se conheceu.

Rajini e Rajendra são oriundos de famílias privilegiadas e eram ela, bióloga, filha de médico, ele, professor na universidade, com formação superior em Oxford, e moravam em um belo bairro no Sri-Lanka. Após sua chegada na França, Rajendra conheceu uma trajetória profissional descontínua, com atividades variadas, primeiramente como operário e almoxarife de loja, e depois, finalmente, trabalhou em um restaurante, após experiência fracassada como proprietário de uma pequena agência de turismo. Rajini, apesar de várias tentativas, nunca conseguiu se inserir profissionalmente na França, como bióloga. Se, devido à reconversão profissional de Rajendra, a 
família parece não viver atualmente grandes dificuldades econômicas, seu nível de vida está longe de ser comparável àquele conhecido em seu país de origem.

A maneira atormentada segundo a qual a instabilidade de sua posição "desclassificada" é vivida por Rajini se traduz na percepção negativa que ela exprime, principalmente, em relação ao bairro do Pavé Neuf, onde seus filhos são educados. Com sua atitude de evitar a vizinhança, Rajini parece buscar demarcar a fronteira que separa esta de sua família. Os filhos (dos quais dois são adolescentes) são proibidos de andar sozinhos e seus colegas nunca são recebidos na casa da família. Falando de sua filha mais velha, ela observa: "Suas amigas the telefonam, mas elas não vêm aqui. Eu não quero muito... eu não quero me relacionar com seus pais." Atribuindo uma importância central ao controle de seus filhos e ao acompanhamento de sua escolaridade, ela busca se distanciar das famílias de seu bairro que não têm as mesmas preocupações:

Por exemplo, quando houve as manifestações, os incêndios do ano passado [outono de 2005], foi dito que era preciso proteger ainda mais os nossos filhos, estar ainda mais vigilantes... principalmente nós, as mães. Mas algumas pessoas não estavam de acordo, porque diziam que não se pode vigiar os jovens durante todo o dia, que não se estava mais nos anos de 1950. Então, eu disse que não estava de acordo, porque os pais não querem fazer seu trabalho. Então, isso abriu dois campos: aqueles que queriam mais severidade e aqueles que diziam que não era o caso. Sendo assim, eu não posso me entender com gente assim.

O mal-estar de Rajini quanto à sua posição instável como também a vontade muito forte de superação das fronteiras sociais que envolvem atualmente a família exprimem-se em seu grande desejo de integração na sociedade francesa - o que se traduz, por exemplo, na escolha dos nomes franceses para seus filhos, ou na preocupação em aprender e preparar regularmente a culinária francesa, para que eles se habituem a ela, e, ainda, nas aspirações profissionais em relação a eles.

\section{Uma trajetória movimentada: superar as "barreiras" e abrir o espírito}

A instabilidade das posiçôes, que é vivida em inúmeros casos com angústia e rejeição, pode, por vezes, ser apreciada como forma de enriquecimento pessoal. Circunstâncias não controladas e até dramáticas podem pro- 
vocar encontros e trocas com pessoas de meios sociais diferentes, e alguns sujeitos tiram dessas experiências uma flexibilidade e uma abertura que eles reivindicam com orgulho.

Membro ativo de uma associação em Noisy le Grand, executiva da Direção Geral da Agência Nacional para o Emprego (Anpe) e mãe de dois filhos, Charlotte, com 51 anos no momento da entrevista, tem uma trajetória particularmente movimentada. Ela expressa muito claramente a preocupação de não se deixar impor fronteiras sociais rígidas; apresenta-se, aliás, como alguém que não coloca "barreiras" entre si e os outros, e que é "antimachista, antiexcisista e antiescravagista de crianças":

As pessoas vêm até mim, porque eu não tenho barreiras. Vou lhes dar um exemplo: muita gente trabalha até tarde, eu fazia isso, em 2001, 2002, quando não queria voltar para casa, e bem, as faxineiras africanas, que estão na sala, e então, a gente se falava, eu thes perguntava como elas estavam, de repente, eu lhes dava coisas. Depois, a gente se tratava por "você", conhecia nossos primeiros nomes, coisas que não se faz, porque eu trabalho na Direção Geral da Anpe, e são apenas os graúdos que trabalham na Direção Geral, e há coisas que não se faz, vocês vêem [...].

Em Arcades [em Noisy le Grand], vocês vêem essa mistura das culturas, e tudo aconteceu muito rapidamente, ao mesmo tempo, nós nos pusemos a freqüentar gente de todos os continentes, jovens, pessoas que não são muito ouvidas por seus pais, e nós (meu novo companheiro e eu) adotamos, entre aspas, com a concordância dos pais, evidentemente, uma jovem cabo-verdiana, aquela que vive com o ucraniano; vamos para o seu país daqui a três semanas.

A curiosidade e mesmo a vontade de estar próximo dos outros e de ajudá-los, Charlotte as deve, sem dúvida, às suas experiências geralmente difíceis e também às "feridas" morais que a marcaram ao longo de sua trajetória (no contexto familiar, ou fora). Acontecimentos foram particularmente marcantes. Assim, quando do falecimento de seu pai - ela tinha 18 anos e acabara de obter seu bacharelado -, ela foi obrigada a ir de porta em porta, com sua mãe, para vender enciclopédias, o que certamente contribuiu para despertar sua "curiosidade pela espécie humana" e sua "vontade de ajudar".

A trajetória de Charlotte é também marcada por uma mobilidade geográfica muito grande: nascida em 1955, no Marrocos, ela viveu até 7 anos "no coração da Argélia". A família veio para a França em 1963. O pai trabalhava na polícia (comandante de brigada), arrastando sua família em freqüentes mudanças de endereço - de Langres, em Haute Marne, a Dijon, 
depois a Vesoul e a Saint-Cloud, por fim, num vilarejo próximo de Bourgen-Bresse, onde o pai morreu. Quando Charlotte se casou, em 1975, ela foi para Belfort e, mais tarde, para Besançon, onde nasceram suas duas filhas. Depois, a família foi para Cahors, onde ela permaneceu mais de doze anos. Duas mudanças a levaram ainda à região parisiense, e depois, a Salon de Provence, antes de se estabelecer em Noisy le Grand.

A mobilidade profissional de Charlotte é impressionante. Depois de ter vendido enciclopédias com sua mãe, ela se tornou recepcionista, depois agente bancária durante quatro anos, vendedora de produtos de beleza, de dietética, agente imobiliária por mais de um ano em Cahors, em seguida foi "preparadora mental para os pilotos de uma fábrica de moto", o que a levava a mudar freqüentemente de empresa, para acompanhar os pilotos. Atualmente, é executiva da Anpe.

Mais ainda do que a mobilidade geográfica ou profissional, o que chama atenção no relato de Charlotte são as situações extremas e os contextos de violência: estupros, tentativa de suicídio, tensão dramática com seu exmarido, duras experiências de saúde. Mas ela também pode evocar dias "ordinários", uma vida familiar calma na casa que ela mesma cuida, acompanhando suas filhas na volta da escola, trocando algumas palavras com o vizinho no caminho e depois voltando para casa com suas filhas, discutindo com elas acontecimentos do dia e preparando um chá.

Não se poderia propor uma explicação muito redutora da recusa que Charlotte opõe às barreiras, de sua rejeição à naturalização das diferentes fronteiras, sociais, de gênero, invocando uma educação primordialmente burguesa, ou uma enorme mobilidade. É toda a sua trajetória - apresentada, aqui, de forma parcial - que deve ser levada em conta em sua complexidade, com as experiências de inúmeras rupturas e os momentos de ligação com a vida familiar, se pretendemos compreender como Charlotte pode, conforme as circunstâncias, ativar mais ou menos intensamente diferentes fronteiras, ou mantê-las como tais.

\section{Burguesia enraizada e burguesia de passagem}

Se as fronteiras com as outras classes são, no conjunto, muito pouco evocadas nas classes privilegiadas, a fronteira que separa uma burguesia mais antiga e estabelecida de uma burguesia mais recente é fortemente fincada nos espíritos e nas representações dos membros da burguesia. Claire, 40 anos, mãe de cinco filhos, habitante de Estrasburgo há doze anos, mas oriunda de 
uma burguesia estabelecida de Bordeaux, exprime o que, em sua opinião, distingue essas burguesias, a saber, a diferença entre o ser e o devir, entre os que são burgueses desde sempre e aqueles que ascendem à burguesia:

Q. - E o que faria, aí, a diferença?

Claire - Eu creio que há pessoas que se tornaram burguesas... que talvez venham de um meio social mais simples e que conseguiram ascender por seus estudos, por seu trabalho e que, de repente, caíram na burguesia. E depois, há nós, que viemos de um meio burguês, de nascença, e que temos isso fincado nos genes e em nossa vida. É isso!

Q. - E essas duas burguesias se encontram? Existem barreiras?

ClAIRE - Elas se encontram! Elas se encontram perfeitamente, mas não se reconhecem! Quer dizer... e não é absolutamente pejorativo o que eu digo. Isso não quer absolutamente dizer que eu... banalize mais que outros, bem ao contrário! Sim, elas sabem reconhecer aquele que chegou, e aquele que é.

O que deixa pressagiar uma forma de "hierarquia" na burguesia, ligada à antiguidade no meio: haveria os que "nasceram burgueses" (os "melhores", ou, em todo caso, os que "promulgam" a norma a que é preciso se ater para fazer parte do meio) e aqueles que se tornam burgueses, ou, então, aprendem a assim ser (os "menos bons", isto é, os que ainda não assimilaram todos os elementos constitutivos da cultura burguesa).

Uma outra fronteira torna-se cada vez mais visível, separando diferentes frações das classes privilegiadas, e é freqüentemente mencionada nas entrevistas, principalmente por aqueles que conheceram a expatriação ou que realizaram várias mudanças de residência ao longo da carreira profissional. Trata-se da fronteira que separa os que "se mexem", móveis - que se vêem e são vistos pelos outros, menos como instáveis do que como outsiders, ou ainda como os que estão "de passagem" -, daqueles que não se movem, que permanecem no lugar, na mesma cidade em que se estabeleceram e se enraizaram há muito tempo. Os segundos, explica Guillaume, marido de Claire, executivo no setor comercial que se tornou consultor em Estrasburgo, e deixou Bordeaux e sua burguesia estabelecida:

Eles permaneceram os mesmos, vêem sempre o mesmo tipo de pessoas, evoluem nos mesmos meios, fazem sempre as mesmas coisas, revêem-se entre si. Então... não há esse distanciamento; sim, eles estão ainda no casulo. Portanto, necessariamente eles não têm essa abertura... inconsciente, porque eles, penso que eles não 
vêem que eles não têm... Nós, a gente vê a mudança profunda entre os que se mexeram e os que não se mexeram [...] são coisas que acontece de sentir... Um pouco como o barco que ficou no porto e o barco que partiu um pouco. Há uma diferença de comportamento em relação a coisas, em relação a fatos... Talvez uma certa hiper precaução, uma timidez de espírito... Sim, penso que é um pouco isso.

As famílias burguesas "de passagem", que têm geralmente gosto por viagens, vêem nessa mobilidade vantagens específicas: um meio de expandir sua rede de conhecimentos, uma descoberta de novas culturas e uma abertura para o mundo. É o caso de Isabelle e de seu marido Philippe, provenientes da região parisiense, mas hoje residentes em Estrasburgo. Eles tiveram um percurso de expatriados, realizaram por duas vezes longas estadias de três anos cada, nos Estados Unidos, em Indianápolis, para onde Philippe havia sido mandado pela empresa multinacional farmacêutica na qual trabalha. Os filhos (13, 10, 8 e 5 anos) freqüentaram uma escola americana, e desde seu retorno à França, em 2002, estudam numa escola internacional. Nos Estados Unidos, a experiência escolar foi "formidável". Para Isabelle, "a abertura para os outros é hiper importante... seja conviver com pessoas um pouco em toda parte, seja... se informar do que se passa lá fora, estar um pouco atento ao que se passa no mundo". Ela aprecia o fato de que a expatriação tenha trazido para seus filhos a "adaptabilidade”. Aliás, ela e seu marido escolheram viver "um pouco à americana" e "experimentar o que o país oferece". Sobretudo, a experiência da expatriação "dá uma abertura de espírito incrível! Quando a gente conhece outras coisas, a gente sai de seu próprio esquema!".

Paradoxalmente, contudo, os membros da burguesia de passagem entrevistados alegam geralmente os traços característicos de seu pertencimento burguês, durante as interações sociais por ocasião das diferentes escolhas que eles devem fazer ao chegar a uma nova cidade (bairro, escola dos filhos, atividades etc.). Tudo acontece como se os membros da burguesia de passagem sentissem a necessidade de trazer em cena símbolos sociais, sinais exteriores ou aparentes de status social, tais como o bairro e a casa onde residem, as atividades de lazer, o domínio dos códigos relacionais, os elementos que vêm reforçar sua identidade burguesa ante a burguesia "estabelecida".

Muito impregnado na burguesia, o "entre si" parece, às vezes, mais importante ainda para os membros da burguesia de passagem do que para os da burguesia mais estabelecida. De fato, estando na cidade geralmente por pouco tempo, os primeiros aceleram de certa forma o ritmo. Residir no 
14.Cf. Barbara Bauchat (2006). Note-se também que os membros da burguesia de passagem entrevistados são, em larga medida, executivos do setor público, e menos amiúde executivos do setor privado ou industrial. Em geral, locatários de seu imóvel principal, uma vez que sua instalação é provisória, eles são, em contrapartida, geralmente proprietários de uma residência secundária, o que revela o desejo de estar fixado, e por um período bastante longo, em um local escolhido ou herdado.

15. Philippe Pierre declara sobre os contextos internacionais que "a mundialização favorece, talvez, as migrações, as trocas de idéias e os empréstimos culturais, mas, ao mesmo tempo, e não apenas entre os excluídos, ela é acompanhada de uma reativação dos traços característicos das comunidades de pertencimento" (2005, s/p). bairro bom, ou matricular seus filhos em boas escolas lhes permite realizar uma economia de tempo, sobretudo no que diz respeito à criação de laços, pois eles são assim assegurados de encontrar as "boas" pessoas, isto é, as pessoas de seu meio ${ }^{14}$.

Assim, uma forte mobilidade residencial ligada às mudanças de posto de trabalho na carreira profissional pode levar a incrementar de diversas maneiras as proteçóes ou as barreiras, a desenvolver a preocupação de evitar grandes rupturas que poderiam comprometer o crescimento dos filhos, a limitar ao máximo os traumas que poderiam estar associados à mobilidade. E sua busca da redução das incertezas passa primeiramente pelo controle das atividades de lazer dos filhos, e da escola, uma escola que garanta um espaço de relações bastante uniforme e que assegure o mínimo de diversidade no interior da homogeneidade social (Saint Martin, 1990). Se eles exercem a mesma profissão, têm o mesmo gênero de vida, as mesmas atividades, os mesmos amigos (ou praticamente os mesmos) nos diferentes países ou cidades percorridos, os membros das classes privilegiadas podem viver como numa bolha ou num paquete "em que tudo está previsto para garantir um passageiro que não saboreia nas escalas senão um exotismo formatado"15 (Lapierre, 2004, p. 19).

\section{Conclusão}

Em um contexto marcado por debates sobre a pertinência do conceito de classe social na análise dos referenciais da sociedade francesa do início do século XXI, a classificação efetuada no início da pesquisa visava a distinguir, de um lado, classes sociais (populares, médias e privilegiadas) e, de outro, no interior dessas classes, posições estáveis e posições instáveis. Depois de ter realizado várias entrevistas, essa primeira classificação foi reconsiderada no sentido de introduzir situações limítrofes ou intermediárias. Os critérios definidos permitiram caracterizar trajetórias e experiências de vida comuns, que se cristalizam em um certo número de fronteiras "objetivas" entre as classes e no interior das classes. Esses critérios não resultam somente de hipóteses sociológicas: os próprios atores também recorreram a eles, por vezes, para definir seu meio de pertencimento e os grupos aos quais eles se opõem, as esperanças de consolidação ou de ascensão social que eles têm para seus filhos. As classes constituem, de certa forma, o fundamento de fronteiras "subjetivas" que permitem aos entrevistados se situarem em relação ao outros grupos sociais. 
Os diferentes grupos não percebem uns aos outros da mesma maneira. Enquanto nas camadas populares, as descriçōes oscilam entre a admiração e a desconfiança em relação às classes privilegiadas, estas parecem mal notar os grupos que não são os seus: elas tendem a ignorar os que estão mais distantes e se abstêm, ao menos na situação de entrevista formal, de fazer julgamentos peremptórios sobre eles. São certamente as classes médias e os grupos intermediários que continuam mais freqüentemente a estabelecer classificaçōes para se referenciar e conferir sentido a uma posição média doravante submetida à instabilidade e à mudança.

São exatamente essas condiçôes sociais em transformação que se exprimem pela heterogeneidade crescente das trajetórias e pela instabilidade daí resultante, com o todo encorajando uma diversificação no interior das classes. As camadas populares estáveis, que tendem a declinar, encontram-se cada vez mais confrontadas com as transformações do mercado de trabalho e com a multiplicidade cultural. As classes médias, já fragmentadas principalmente entre classes médias do público e classes médias do privado, diversificam-se pela ascensão de alguns de seus membros e pela queda de outros. As elites conhecem a escalada potencial daqueles que atuam em redes internacionais e com grande mobilidade, enquanto os técnicos ganham importância, diversificam-se entre si e se "medianizam".

Um ponto metodológico parece importante de observar para uma pesquisa voltada às percepções subjetivas das fronteiras sociais. Quando o fosso aberto entre as classes é muito profundo, isso pode acarretar uma espécie de nevoeiro sobre os pólos opostos da escala social. Assim, em determinados subúrbios, os ricos e as elites parecem às vezes desaparecer da paisagem social: inacessíveis ao encontro e ao olhar, eles deixam assim seu papel, como figuras de admiração e de oposição, aos vizinhos franceses, membros das classes médias e populares percebidas como estabelecidas. Enquanto os privilegiados podem se redobrar em seus guetos de luxo, os antagonismos socioculturais sobrepõem-se aos antagonismos socioeconômicos.

O caráter fluido e complexo dessas experiências exige dos atores um trabalho de coerência e de adaptação. As dificuldades revelam-se nos discursos por vezes contraditórios dos entrevistados, mostrando até que ponto suas identidades pessoal e social se encontram comprometidas. Os membros dos meios populares buscam se diferenciar dos imigrantes mais pobres e mais precários, sentem sua identidade ameaçada ou apelam para a solidariedade. Os membros das classes privilegiadas constatam e apreciam a aber- 
tura de espírito associada a encontros diversos e variados, mas estabelecem ativamente um "entre si" particularmente seletivo.

As trajetórias e as experiências analisadas permitem constatar que as identificações e as fronteiras de classes certamente enfraqueceram, mas não desapareceram. Cada grupo social pode ser caracterizado por uma experiência desigual da instabilidade, e algumas rupturas, às quais os atores atribuem uma avaliação positiva, podem contribuir para desenvolver disposições de superar as fronteiras sociais, ou ao menos não naturalizá-las. Ainda é cedo para afirmar que essas cisões e experiências diversas se tornarão mais usuais e, nesse sentido, que elas permitirão novas clivagens de identificação. Em todo caso, a experiência da instabilidade e o trabalho de reflexão que ela promove podem também ser analisados sob esse ângulo, possibilitando, talvez, a emergência de novos princípios de justiça e de integração, que não foram plenamente compreendidos na noção de classe, tal como ela foi definida até o momento.

\section{Referências Bibliográficas}

Barth, Fredrik. (1995), Ethnic groups and boundaries. In: Poutignat, Philippe \& STREIFF-FENART, Jocelyne (orgs.). Théories de l'ethnicité. 1ํㅡㄹ edição 1969. Paris, PUF, pp. 203-249.

BAUCHAT, Barbara. (2006), "La bourgeoisie aujourd'hui: entre mobilité et ancrage". Comunicação apresentada no colóquio da Associação Francesa de Sociologia. Bordeaux, Réseau thématique n. 5, set.

BolTANSKi, Luc. (1993), La souffrance à distance. Paris, Métailié.

Bouffartigue, Paul. (2004), Le retour des classes sociales: inégalités, dominations, conflits. Paris, La Dispute/Snedit (col. États des Lieux).

Bourdieu, Pierre. (1979), La distinction: critique sociale du jugement. Paris, Minuit. . (1987). "Espace social et pouvoir symbolique". In: Choses dites. Paris, Minuit.

CASTEL, Robert. (1995), Les métamorphoses de la question sociale: chronique du salariat. Paris, Fayard. \& Haroche, Claudine. (2001), Propriété privée, propriété sociale, propriété de soi. Paris, Fayard.

Chauvel, Louis. (2006), “Classes sociales”. In: Mesure Sylvie \& SAvidan, Patrick (orgs.). Le dictionnaire des sciences humaines. Paris, PUF, pp. 150-152.

Elias, Norbert \& SCOTson, John. (1997), Logiques de l'exclusion. 1a edição 1965. Paris, Fayard. 
Lagrange, Hugues (dir.). (2006), L'épreuve des inégalités. Paris, PUF (col. Le Lien Social).

LaPierre, Nicole. (2004), Pensons ailleurs. Paris, Stock.

LE WitA, Béatrix \& SjöGREN, Annick. (1987), "La bourgeoisie, tabou et fascination”. In: Gutwirth, Jacques \& Petonnet, Colette (eds.). Les chemins de la ville: enquêtes ethnologiques. Paris, Editions du CTHS, pp. 171-187.

LojKine, Jean. (2005), L'adieu à la classe moyenne. Paris, La Dispute.

Maurin, Eric. (2004), Le ghetto français: enquête sur le séparatisme social. Paris, Seuil. PAKULSKI, Jan. (1993), “The dying of class or of marxist class theory?”. International Sociology, 3 (8): 279-292.

Pierre, Philippe. (2005), "Mobilité internationale et identité des cadres: pour une sociologie 'immergée': des usages de l'ethnicité dans l'entreprise mondialisée". Site http://espacestemps.net/document1455.html, consultado em 24/1/2008.

Saint Martin, Monique de. (1990), “Une ‘bonne’ éducation”. Ethnologie Française, 1: 62-70, jan.-mar.

\& Gheorghiu, Mihaï Dinu (coords.). (2007), "Education et production des frontières sociales: familles, monde associatif et institutions scolaires". Paris, Ehess/ Cems.

SENNETT, Richard. (2000), Le travail sans qualités: les conséquences humaines de la flexibilité. Paris, Albin Michel.

Thompson, Edward P. (1988), La formation de la classe ouvrière anglaise. $1^{\underline{a}}$ edição 1963. Paris, Ehess-Gallimard-Seuil.

Tilly, Charles. (2004), "Social boundary mechanism”. Philosophy of Social Sciences, 2 (34): 211-236.

. (2005), Identities, boundaries, and social ties. Boulder/Londres, Paradigm Publishers.

URRY, John. (2005), Sociologie des mobilités: une nouvelle frontière pour la sociologie? Paris, A. Colin.

WaGner, Anne-Catherine. (1998), Les nouvelles élites de la mondialisation: une immigration dorée en France. Paris, PUF.

. (2007), Les classes sociales dans la mondialisation. Paris, La Découverte (col. Repères). 


\section{Resumo}

Trocas intergeracionais e construção de fronteiras sociais na França

$\mathrm{Na}$ sociedade francesa contemporânea, as antigas desigualdades perduram e novas desigualdades se manifestam, particularmente com a desestabilização crescente das posições sociais e profissionais ocupadas. A noção de fronteira revela-se, assim, essencial: as fronteiras delimitam os contornos das categorias sociais, mas abrem também espaços de troca e de encontro. Buscando apreender os processos de construção e/ou de fragilização das fronteiras sociais, uma pesquisa qualitativa foi realizada junto a famílias (pais e jovens) de diferentes grupos sociais, com interesse pela construção simbólica e percepção das fronteiras entre as diferentes classes sociais, e também sua construção no interior das mesmas. As classes sociais continuam a constituir o fundamento de fronteiras "subjetivas". No entanto, o caráter fluido e complexo das experiências sociais exige dos atores mais trabalho de coerência e de adaptação.

Palavras-chave: Classes sociais; Fronteira social; Instabilidade das posiçôes; Hierarquias sociais; Trocas geracionais; França.

\section{Abstract}

Social boundaries and the instability of positions in France

In contemporary French society, traditional inequalities persist while new ones have emerged, particularly as a result of the growing destabilization of social and professional positions. The notion of boundary therefore becomes essential: boundaries delimit social categories, but also open up spaces for encounters and exchanges. Seeking to comprehend the processes of constructing and/or weakening social boundaries, a

Texto recebido em $1 /$ 2/2007 e aprovado em $1 / 2 / 2008$.

Monique de Saint Martin, Ehess/Cems. E-mail: monique.desaint-martin@ehess.fr. Daniella de Castro Rocha, Université d'Evry/ Cems. E-mail: daniella @free.br.

Mariana Heredia, Conicet/UBA-Idaes/ Cems. E-mail: heredia. mar@gmail.com. qualitative research study was carried out with families (parents and young people) of different social groups, centred on the symbolic construction and perception of the boundaries between different social classes, and on their construction within these classes. Do social classes still constitute the bases for subjective boundaries? The article concludes that the fluid and complex nature of social experiences means the need for more work at connecting and adapting from the actors.

Keywords: Social Classes; Social Boundary; Instability of Positions; Social Hierarchies; France. 